\title{
Nanoscopic Hardness Measurement by Atomic Force Microscope*
}

\author{
Nobuo NAGASHIMA**, Saburo MATSUOKA** \\ and Kensuke MIYAHARA**
}

\begin{abstract}
Atomic force microscopes (AFMs) can be used for atomic-scale imaging and nanofabrication. Taking advantage of this we developed a nanoindentation technique. Hardness measurements were carried out on cementite spheroidized $S 25 \mathrm{C}$ carbon steel (Vickers hardness $\left.H_{V}=128\right)$ and $400^{\circ} \mathrm{C}$-tempered SNCM 439 low alloy steel $\left(H_{V}\right.$ $=414$ ), using a cantilever with a three-sided pyramidal diamond tip. The depth of indentations created was between 14 and $330 \mathrm{~nm}$. The difference in hardness between $S 25 \mathrm{C}$ and SNCM 439 steels was detected in the nanoscopic region. From these results, it was concluded that nanoindentation was realized with AFM.
\end{abstract}

Key Words: S25C Steel, SNCM 439 Steel, Atomic Force Microscope, Atomic Scale Imaging, Nanofabrication, Ilardness Measurement

\section{Introduction}

Hardness measurement is generally conducted to evaluate basic properties of structural materials, because of its simplicity and reliability. Hardness has good correlation to the tensile strength or fatigue strength of structural materials, and is used to estimate aged materials ${ }^{(1),(2)}$. In recent years, the demand for hardness measurement ahead of the crack tip or around fibers to facilitate understanding of the damage process of advanced materials has increased. Hardness measurement of thin film structures used in semiconductor devices and magnetic storage devices is also important. Accordingly, it is necessary to develop an ultramicro hardness test method for the nanoscopic region ${ }^{(3)}$.

Both scanning tunneling microscopes (STMs) ${ }^{(4)}$ and atomic force microscopes (AFMs) ${ }^{(5)}$ have atomic

* Received 9th November, 1995. Japanese original: Trans. Jpn. Soc. Mech. Eng., Vol.61, No. 582, A (1995), pp. 416 422. (Received 21st June, 1994)

** Environmental Performance Division, National Research Institute for Metals, 121 Sengen Tsukuba shi, Ibaraki 305, Japan resolution and can be used for nanoscopic fabrication. Taking advantage of this, STM and AFM have been applied to ultramicro-hardness measurement ${ }^{(6)-(8)}$. From a viewpoint of hardness measurement, the AFM is superior to the STM, because the AFM can be used to measure force of $\mathrm{nN}$ order ${ }^{(6),(7)}$. However, there remain some problems for the application of AFMs to hardness measurement. For instance, (1) the indenter configuration is not known, because a tungsten tip polished electro chemically is used ${ }^{(6)}$. (2) An indentation image is not obtained ${ }^{(6)}$. (3) The measurement is not done on materials in practical use ${ }^{(6),(i)}$. On the other hand, Nagashima et al. ${ }^{(8)}$ conducted a hardness test by STM using a three-sided pyramidal diamond tip, on cementite spheroidized S $25 \mathrm{C}$ carbon steel. After creation of $16 \times 16$ indentations and imaging of them, the hardness was found to be much higher in the cementite portion than in the ferrite portion. However, the indentation force was not measured in the test.

In this study, hardness measurement by AFM using a cantilever with a three sided pyramidal diamond tip was performed for a cementite spheroidized $\$ 25 \mathrm{C}$ carbon steel, and $400 \mathrm{C}$ tempered SNCM 439 
low alloy steel. The ultramicro-hardness values obtained were compared with the macro-hardness values measured by a conventional Vickers hardness tester.

\section{Vickers Hardness Test}

Various hardness tests such as Vickers, Brinell, Knoop and Rockwell are known. The Vickers hard ness test is often used for ultramicro-hardness measurements. In the Vickers hardness test, the sample surface is indented using a pyramidal diamond in denter, as shown Fig. 1. Vickers hardness, $H_{v}$, is defined by

$$
H_{v}=0.102 \mathrm{~F} / \mathrm{S} \text {, }
$$

where $F$ is the indentation force $(N)$ and $S$ is the surface area of the indentation $\left(\mathrm{mm}^{2}\right)$. Since a three sided pyramidal diamond indenter as shown in Fig. 1 (b) was employed in this study, the surface area, S, is given as

$$
\begin{aligned}
S & =9 h^{2}(\tan \theta / 2) /\left\{3-(\tan \theta / 2)^{2}\right\} \\
& =l^{2} /(\tan \theta / 2),
\end{aligned}
$$

where $h, l$ and $\alpha$ are the depth $(\mathrm{mm})$, length $(\mathrm{mm})$ and edge angle (degree) of the three-sided pyramidal indenter shown in Fig. 1(b).

According to the Japanese Industrial Standards (JIS), the Vickers hardness test is conducted using a four-sided pyramidal diamond indenter with a facing angle of $136^{\circ(9)}$. The hardness is determined by measuring the diagonal distance, $l$, of the indentation using an optical microscope, as shown in Fig. 1(a). In the micro-hardness test performed using the DUH 200 system, the details of which will be described in the next section, the length, $l$, of the three-sided pyramidal indentation in Fig. $1(\mathrm{~b})$ is also measured using the optical microscope. In such a region as the indentation region which is measured using the optical microscope, the elastic deformation during the hardness test is negligible, as compared with the plastic deformation. In this study, however, the elastic deformation was not negligible, because the hardness

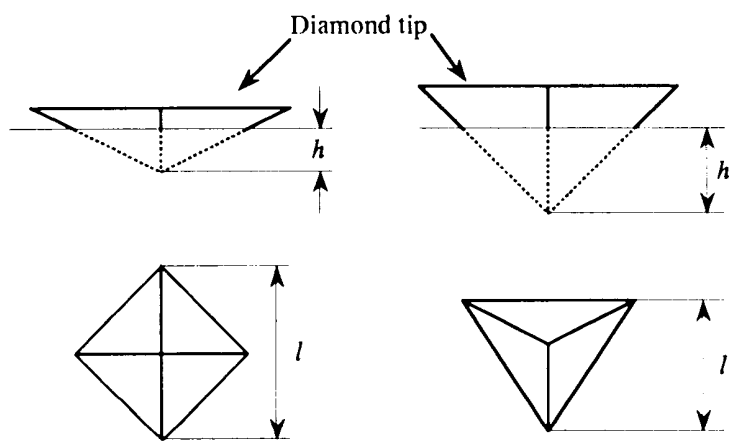

(a) JIS standards (b) DUH 200 and AFM

Fig. 1 Two indenters used in Vickers hardness test measurement was conducted by $A F M$ at a force lower than $100 \mu \mathrm{N}$. In such a region, the elastic deformation was estimated using FEM analysis for the elastic indentation by Murakami et al.(3) The relationship between indentation force, $F(\mathrm{mN})$, and indentation depth, $h_{e}(\mu \mathrm{m})$, for the three-sided pyramidal indenter is given by

$$
F=1.7 C h_{e}^{2} \text {, }
$$

where

$C=\left[2 E /\left\{\pi\left(1-\nu^{2}\right)\right\}\right] \tan \alpha$.

$E$ is Young's modulus (GPa), $\nu$ is Poisson's ratio and $\alpha$ is the angle formed by the face and central axis (degree).

\section{Experimental Procedure}

\section{1 Materials}

The materials employed were a cementite spheroidized S25C carbon steel, and $400 \mathrm{C}$-tempered SNCM439 low alloy steel. Figure 2 shows SEM images of both materials etched chemically in a solution of $3 \%$ nitric acid and $97 \%$ alcohol. In the case of the $\$ 25 \mathrm{C}$ steel in Fig. $2(\mathrm{a})$, white spherical particles are cementite and others are ferrite. Figure $2(\mathrm{~b})$ shows that the SNCM 439 steel is tempered martensitic.

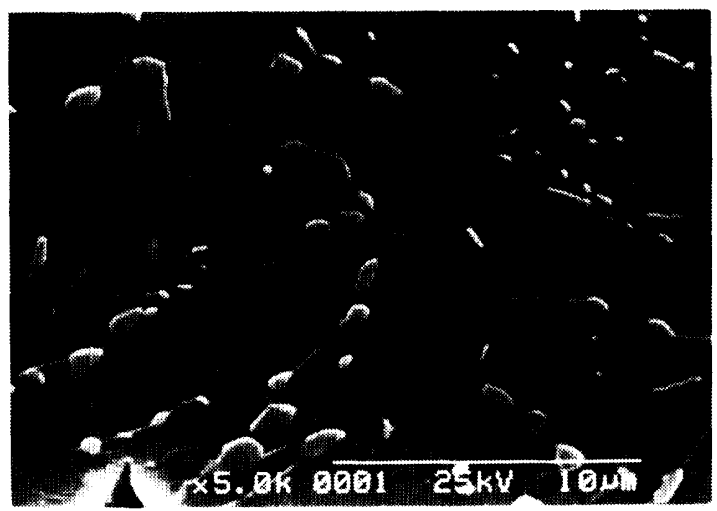

(a) S25C steel

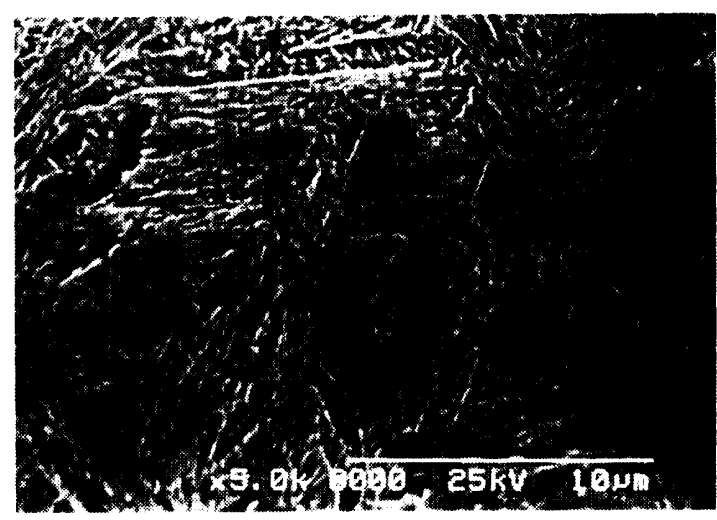

(b) SNCM 439 steel

Fig. 2 SEM images of specimen surfaces etched in a solution of $3 \%$ nitric acid and $97 \%$ alcohol 


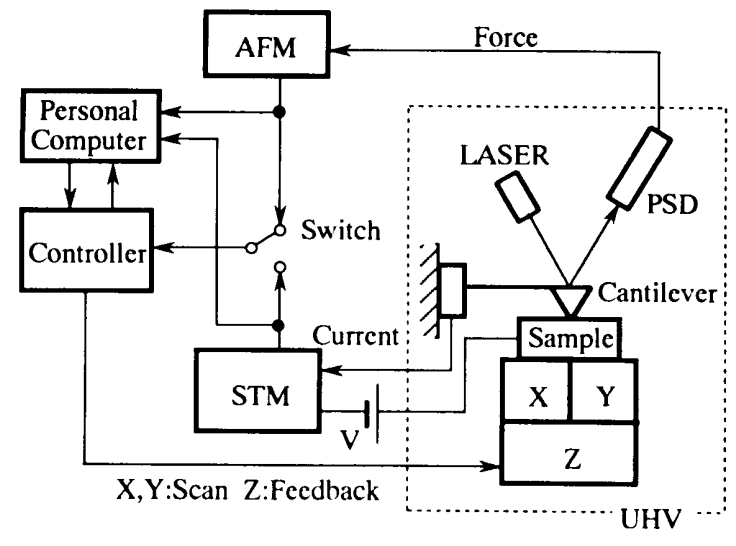

Fig. 3 Block diagram of AFM/STM system

Vickers hardness values, $H_{V}(30)$, were 128 and 414 for S $25 \mathrm{C}$ and SNCM 439 steels, respectively.

Hardness tests were carried out on the surfaces polished using alumina particles of $0.04 \mu \mathrm{m}$ diameter for both steels. Needless to say, the surfaces were not etched in the solution of $3 \%$ nitric acid and $97 \%$ alcohol.

\section{2 Hardness tests}

Figure 3 shows a diagram of the AFM/STM system used for hardness tests. In AFM, a topographic image is obtained by scanning a cantilever with a sharp tip in the $x$ and $y$ directions, while the attractive or repulsive force between sample and tip is kept constant. In this study, the repulsive force was measured by the optical lever technique to obtain AFM images. The system in Fig. 3 can be used as an STM system when the cantilever is conductive. The cantilever, sample and actuator are set in an ultrahigh vacuum chamber of $10^{-8} \mathrm{~Pa}$. In this study, however. the observation was done in air, using an actuator with scanning ranges in the $x, y$ and $z$ directions of 9 $\times 9 \times 3 \mu \mathrm{m}$.

In order to apply AFM to the hardness measurement, it is necessary to use a stiff cantilever with a three- or four-sided pyramidal tip. In Fig. 4 is shown an SEM image of the cantilever used in this study. A three-sided pyramidal diamond indenter with an edge angle of $60^{\circ}$ is fixed on the end of the lever. Two different levers made of SUS 304 stainless steel films were used. One is $1 \mathrm{~mm}$ wide and $20 \mu \mathrm{m}$ thick, and the other is $1 \mathrm{~mm}$ wide and $50 \mu \mathrm{m}$ thick. The maximum forces for the 20 and $50 \mu \mathrm{m}$ thick levers were 50 and $240 \mu \mathrm{N}$, respectively, when the lengths were 1.4 and $2.5 \mathrm{~mm}$. The 20 and $50 \mu \mathrm{m}$ thick levers were designated the No. 1 and No. 2 levers, respectively.

Figure 5 shows the procedure for hardness measurement by AFM. At point (a), the tip of the indenter is moved to a desired location under a low repulsive force, by which the sample surface is not

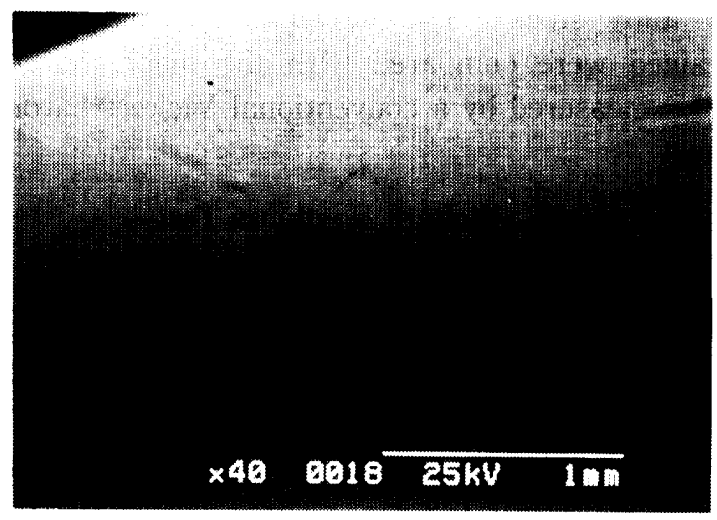

Fig. 4 SEM image of diamond cantilever

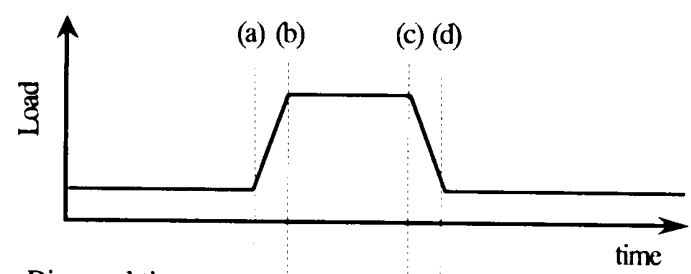

Diamond tip

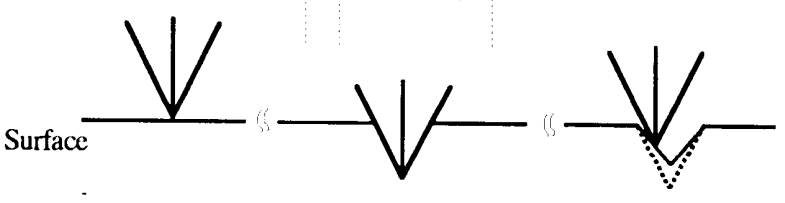

Fig. 5 Procedure for hardness measurement by AFM

modified. Between points ( $a$ ) and ( $b$ ), indentation is conducted at a constant force speed of $55.5 \mu \mathrm{N} / \mathrm{sec}$. Between points ( $b$ ) and ( $c$ ), the maximum force is kept constant for $4.5 \mathrm{sec}$. Between the points (c) and (d), the indenter is retracted at the same force speed as that for loading. Finally, an AFM image of the indentation is obtained by scanning the cantilever at above mentioned low repulsive force. We assumed that it was possible to obtain a proper image of the indentation using the same indenter, because the indentation becomes shallow due to the elastic recovery during unloading, as compared with the diamond indenter shape.

In addition to the AFM indentation, hardness tests were carried out using a micro hardness tester (DUH-200, Shimadzu Co. Ltd., Japan). The three sided pyramidal diamond indenter with an edge angle of $115^{\circ}$ was used in this tester. The hardness was determined from the relationship between indentation force and penetration depth. An optical microscope was also installed to measure the size of the indentation.

\section{Experimental Results}

\section{1 Surface modification during AFM imaging}

Figure 6 shows an AFM image of an area of $9 \times 9$ 
$\mu \mathrm{m}$ on the ferrite portion of the $\mathrm{S} 25 \mathrm{C}$ steel scanned at a force of $2.5 \mu \mathrm{N}$, after scanning four different areas of $1 \times 1 \mu \mathrm{m}$ at four different forces of 8.3, 16.7, 33.4 and 50 $\mu \mathrm{N}$, respectively, with the No. 1 lever. The ferrite portion was not modified at a force of $8.3 \mu \mathrm{N}$, while square hollows were formed when the force was 16.7 $\mu \mathrm{N}$ or higher. Accordingly, it was concluded that scanning at a force lower than or equal to $8.3 \mu \mathrm{N}$ had no effect on the surface morphology of the ferrite portion of $\mathrm{S} 25 \mathrm{C}$ steel. This also holds for the cementite portion of S $25 \mathrm{C}$ steel and SNCM 439 steel, because their hardness is higher than that of the ferrite portion of $\mathrm{S} 25 \mathrm{C}$ steel. In the following $\mathrm{AFM}$ observations, therefore, the imaging forces were 2.5 $\mu \mathrm{N}$ for the $\mathrm{No} .1$ lever and $8 \mu \mathrm{N}$ for the $\mathrm{No} .2$ lever.

\section{2 Hardness measurement}

Figure 7 shows a reversed AFM image of an indentation obtained on the ferrite portion of $\mathrm{S} 25 \mathrm{C}$ steel after the hardness test at a maximum force of $240 \mu_{\mathrm{N}}$ with the No. 2 lever. The image was reversed

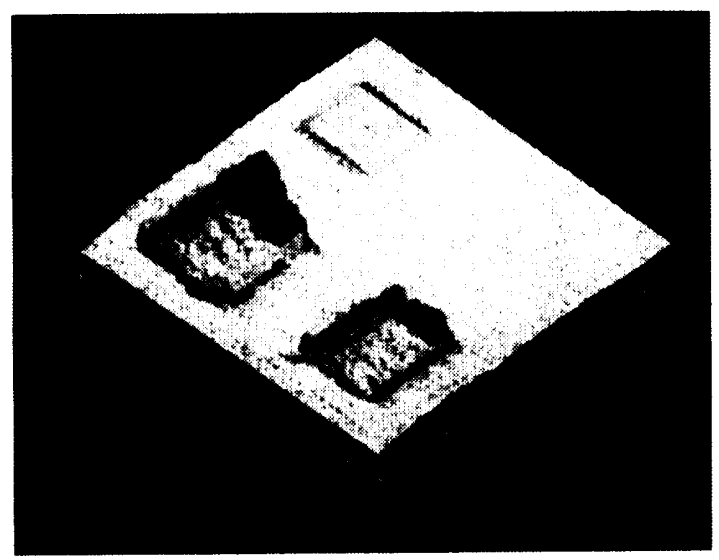

Fig. 6 AFM image over an area of $9 \times 9 \mu \mathrm{m}$ for $\$ 25 \mathrm{C}$ steel, after scamning four areas of $1 \times 1 \mathrm{~m}$ at four different force conditions of $8.3,16.7,33.4$ and 50 $\mu \mathrm{N}$

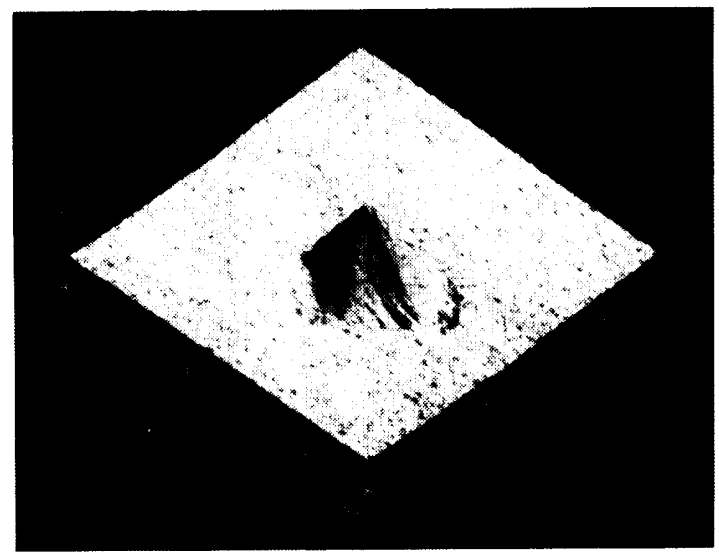

Fig. 7 Reversed AFM image of the indentation created at a force of $240 \mu \mathrm{N}$ on the surface of $S 25 \mathrm{C}$ steel to facilitate visualization of the shape of the indentation. The indentation was shaped like a three-sided pyramid with an edge angle of $60^{\circ}$ which was identical to the shape of the indenter, and its depth was $330 \mathrm{~nm}$. In addition, the hollow portion around the indentation was the plastic deformation region.

Figure 8 shows an AFM image of $3 \times 3$ indentations on the ferrite portion of $\mathrm{S} 25 \mathrm{C}$ steel after multiple hardness tests at a maximum force of 33.4 $\mu \mathrm{N}$ with the No. 1 lever. Indentations were not necessarily three sided pyramidal in shape. The average depth of the indentations was about $14 \mathrm{~nm}$. The uneven pattern parallel to the indentation rows is considered to be scratch marks caused by alumina polishing.

Figure 9 shows the relationship between indentation force and indentation depth obtained in AFM hardness tests on the ferrite portion of $\$ 25 \mathrm{C}$ steel $(\triangle)$ and on the surface of SNCM 439 steel $(O)$. The rela. tionship for S $25 \mathrm{C}$ steel obtained using the DUH-200 hardness tester is also shown $(\nabla)$. The hardness, $H_{v}$,

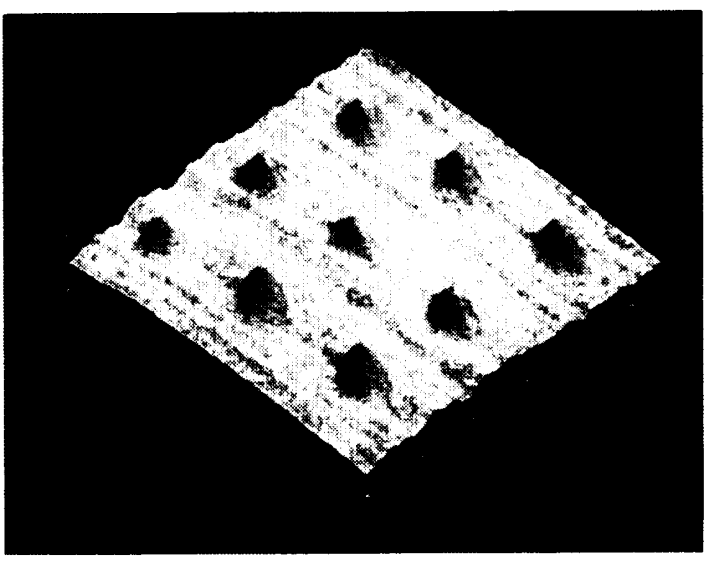

Fig. \& Reversed AFM image of indentations created at a force of $33.4 \mu \mathrm{N}$ on the surface of $\$ 25 \mathrm{C}$ steel

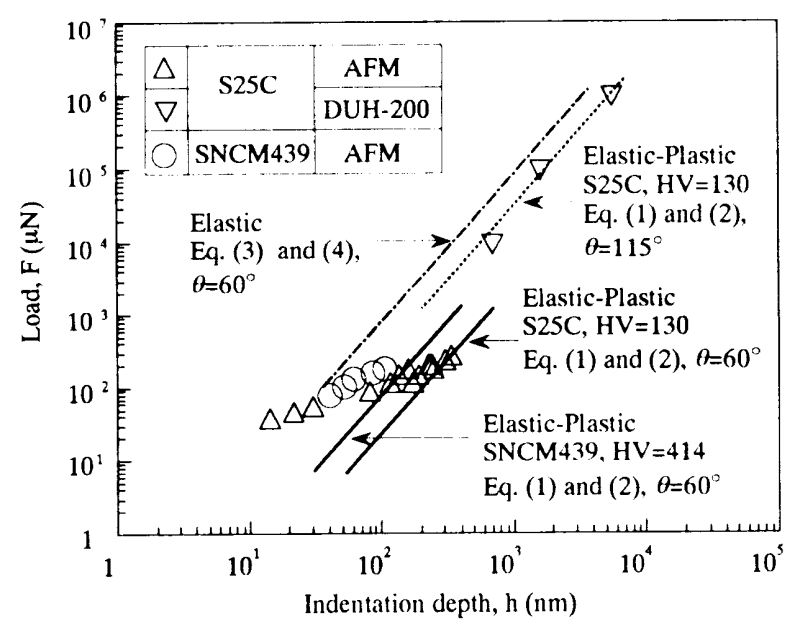

Fig. 9 Relationship between indentation force and depth 
of $\$ 25 \mathrm{C}$ steel obtained using the DUH-200 tester was 130 , which coincided with the hardness $H_{v}(30)$ of 128 at a force of $30 \mathrm{kgf}$ obtained with an ordinary Vickers hardness tester. In Fig. 9 are also shown the relation. ships between indentation force and depth calculated using Eqs. (1) and (2) and Eqs. (3) and (4). The dotted line, the relationship for $\mathrm{S} 25 \mathrm{C}$ steel, is obtained by calculation, substituting the hardness, $H_{V}$ $=130$, and the edge angle of the indenter, $\theta=115^{\circ}$, into Eqs. (1) and (2). Two solid lines representing $\mathrm{S} 25 \mathrm{C}$ and SNCM 439 steels were obtained by calculation, substituting $\theta=60^{\circ}$ and $H_{v}=130$ and 414 into Eqs. (1) and (2). The dot-dashed line shows the elastic relationship between indentation force and depth from FEM analysis by Murakami et al.(3), which was calculated using Eqs. ( 3$)$ and ( 4 ), and $E=208 \mathrm{GPa}, \nu=$ 0.3 and $\alpha=19.5$.

As shown in Fig. 9, the experimental results $(\nabla)$ for $\mathrm{S} 25 \mathrm{C}$ steel obtained using the DUH-200 tester coincide with the calculation results. This is due to the fact that using the DUH-200 tester the hardness is measured so as to satisfy Egs. (1) and (2). In the case of AFM hardness measurements, the experimental results $(\triangle, O)$ for $S 25 \mathrm{C}$ and SNCM 439 steels at higher forces agreed with the calculation results. However, the experimental results gave higher values for both steels than the calculated results, when the force was lower. One reason for this seems to be that the elastic deformation is neglected in the AFM hardness measurement in which the indentation depth after unloading is measured. Therefore, the elastic indentation depth from FEM analysis was added to the results of AFM measurements. In Fig. 10 are shown the modified relationship between indentation force and depth for S 25 C and SNCM 439 steels as indicated by $\triangle$ and $O$, respectively. In addition, the

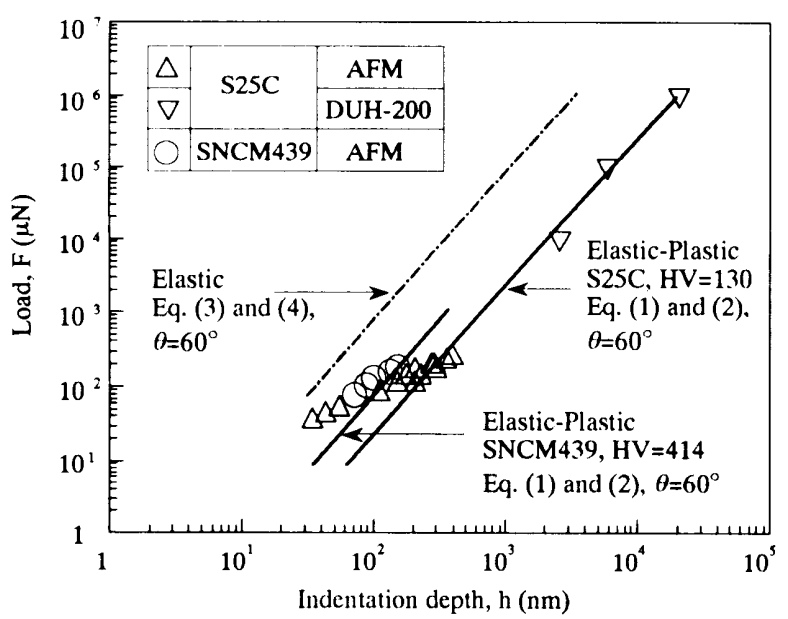

Fig. 10 Modified relationship between indentation force and depth edge angles of indenters are $60^{\circ}$ for $\mathrm{AFM}$ and $115^{\circ}$ for the DUH-200 tester. In order to compare these results with each other, the indentation depth $h_{115}$ for $\theta=115^{\circ}$ (DUH - 200 tester) was converted to the depth $h_{60}$ for $\theta$ $=60^{\circ}$ which yields the same surface area, using follow. ing equation.

$$
h_{60}=h_{115} \sqrt{\frac{(\tan 57.5 / \tan 30)}{\left\{3-(\tan 57.5)^{2}\right\} /\left\{3-(\tan 30)^{2}\right\}}}
$$

Needless to say, the conversion results $(\nabla)$ for $\mathrm{S} 25 \mathrm{C}$ steel using the DUH -200 tester in Fig. 10 coincided with the solid line calculated using Eqs. ( 1 ) and (2). Comparing the results of AFM measurements $(\triangle, O)$ with the calculated result (solid line), agreement was observed in the range of $F>80 \mu \mathrm{N}$ and $\mathrm{h}>$ $110 \mathrm{~nm}$ for $S 25 C$ steel and $F>160 \mu \mathrm{N}$ and $h>129 \mathrm{~nm}$ for SNCM 439 steel. Accordingly, it is concluded that the hardness measurement by AFM is effective in such a micro range, using the cantilever with a three-sided pyramidal diamond tip. In the lower force region,

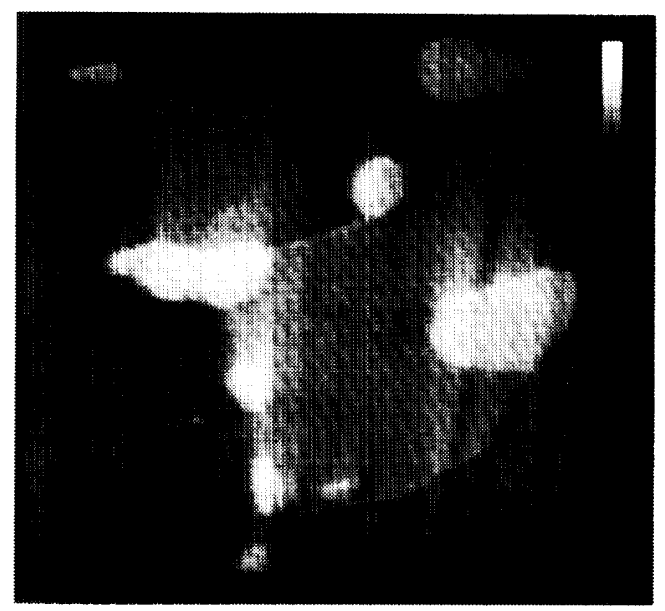

Fig. 11 AFM image of the surface of S $25 \mathrm{C}$ steel etched in the solution of $3 \%$ nitric acid and $97 \%$ alcohol

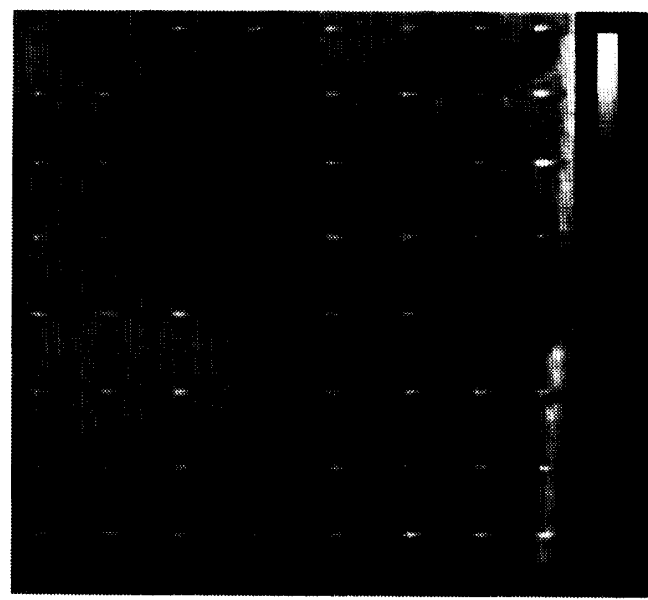

Fig. 12 Reversed AFM image of $8 \times 8$ indentations created at a force of $40 \mu \mathrm{N}$ on the etched surface of $\$ 25$ C steel 
however, AFM measurements gave higher values than the calculated results for both $\mathrm{S} 25 \mathrm{C}$ and SNCM 439 steels. This will be discussed in the next section.

\section{3 Hardness distribution}

Figures 11 and 12 are AFM images of S $25 \mathrm{C}$ steel before and after examination of the hardness distribution by AFM. The surface was lightly etched in the solution of $3 \%$ nitric acid and $97 \%$ alcohol so that cementite particles were visible. Cementite particles can be distinguished as the bright portions in Fig. 11.

At a pitch of $1 \mu \mathrm{m} 8 \times 8$ indentations were created on the etched surface at a force of $40 \mu \mathrm{N}$ by AFM. Figure 12 shows an AFM image after creation of $8 \times$ 8 indentations. This image was reversed in order to emphasize the indentations. No indentations were visible on cementite particles, which corresponded to the dark portions in Fig. 12. On the other hand, indentations with a depth of about $45 \mathrm{~nm}$ were created on the ferrite portion. From these results it is apparent that the hardness distribution can be measured for the materials which have particles of a few $\mu \mathrm{m}$ in diameter, using AFM and the cantilever with the pyramidal diamond tip. Burnham and Colton ${ }^{(6)}$ measured the hardness of gold using AFM and a nickel tip and reported that one important development is to obtain AFM images of indentations, because the hardness is determined from the indentation shape in the Japanese Industrial Standards. Figures 7 and 8 as well as Fig. 12 show that our AFM hardness measurement was improved, because AFM images of indentations were obtained.

\section{Discussion}

As shown in Fig. 10, three data obtained from the ferrite portion of $S 25 \mathrm{C}$ steel in AFM hardness measurement tests at forces lower than $80 \mu \mathrm{N}$ were much higher than the calculation result expressed by the solid line. According to Eqs. ( 1 ) and (2), this implies that the hardness increases as the force decreases. Similar results have been obtained by Pethica et al. ${ }^{(10)}$ One cause of this is that the tip of the indenter is rounded. The radius of curvature of the tip of the pyramidal diamond indenters used in this experiment is guaranteed to be less than $100 \mathrm{~nm}$.

Assuming that a sphere of radius $R$ exists at the tip of the pyramidal diamond indenter, the surface area, $S_{R}$ is given by

$$
S_{R}=2 \pi R h_{R}
$$

where $h_{R}$ is the indentation depth for the case when only the spherical portion of the pyramidal diamond indenter is indented. Equation ( 5 ) was derived under the assumption that the surface areas of two pyramidal indenters with different edge angles were equal at a given indentation force. According to the same

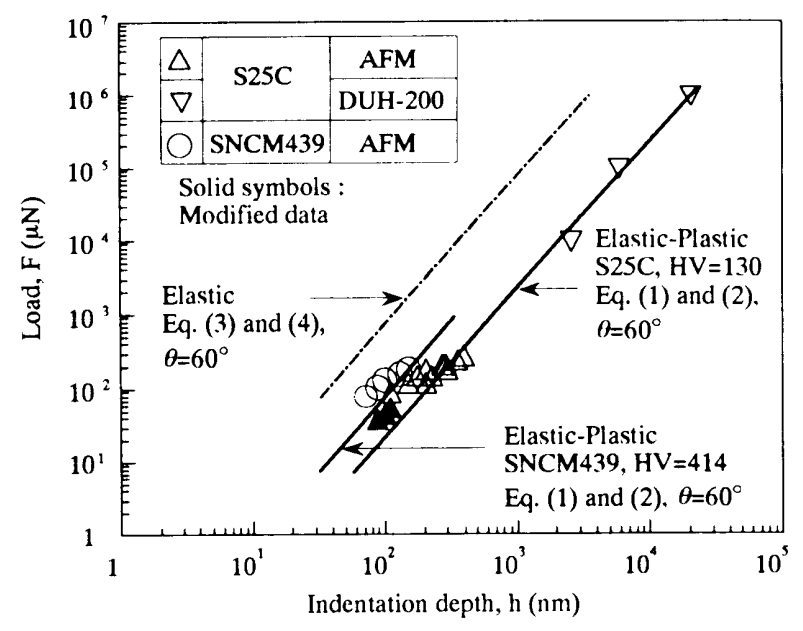

Fig. 13 Relationship between indentation force and depth. Three data for S25C steel $\Delta$ were modified, considering a dull tip

assumption, the depth of the sphere, $h_{R}$, is converted to the depth of the three sided pyramid, $h$, from Eqs. (2) and (6)

$$
h=\sqrt{2 \pi R h_{R}\left\{3-(\tan \theta / 2)^{2}\right\} / 9(\tan \theta / 2)}
$$

The indentation depth for AFM hardness measurements was converted, substituting $\theta=60^{\circ}$ and $R=$ $70 \mathrm{~nm}$ into Eq. $(7)$. Here, the radius $R=70 \mathrm{~nm}$ was determined by trial and error, and was nearly equal to the guaranteed radius of $R=100 \mathrm{~nm}$. Therefore, the conversion is not valid at indentation depths greater than $70 \mathrm{~nm}$ in Fig. 10. In Fig. 13 are shown the converted relationship between indentation force and depth. Three data at the lower forces for $\$ 25 \mathrm{C}$ steel were converted and expressed as $\mathbf{\Delta}$. Other data were not converted and expressed as $O$ and $\triangle$ for $S 25 \mathrm{C}$ and SNCM 439 steels, respectively. The experimental results for $S 25 \mathrm{C}$ steel agreed well with the calculated result (solid line). Accordingly, it is found that a sharp indenter is required in order to perform accurate ultramicro-hardness measurement using AFM.

The specimen surface was polished using emery paper and alumina particles in this study. It is known that the hardness near the specimen surface is increased by polishing. This surface hardening could influence the ultramicro-hardness measurement results. The hardening effect will be studied in the future.

\section{Conclusion}

Ultramicro-hardness tests were conducted for cementite spheroidized S $25 \mathrm{C}$ carbon steels, and $4010^{\circ} \mathrm{C}$ tempered SNCM 439 low alloy steel, using AFM and a cantilever with a three sided pyramidal diamond indenter with an edge angle $60^{\circ}$. The conclusions obtained are as follows: 
(1) AFM hardness measurements were conducted in the range of indentation force lower than 240 $\mu \mathrm{N}$ and indentation depth smaller than $330 \mathrm{~nm}$. The force and depth were smaller by an order of magnitude than those in the ordinary micro-Vickers hardness test. Accordingly, it was concluded that nanoindentation is realized by AFM. Furthermore, it was found that a cantilever with a sharp diamond indenter is required in order to achieve AFM nanoindentation. The radius of curvature of the tip of the diamond indenter used in this study was estimated to be $70 \mathrm{~nm}$.

(2) In an attempt to make $8 \times 8$ indentations in a region of $8 \times 8 \mu \mathrm{m}$ on the surface of $\mathrm{S} 25 \mathrm{C}$ steel, no indentations were visible on the small cementite particles, while indentations with a depth of about $45 \mathrm{~nm}$ were created on the ferrite portion. It was concluded that the hardness distribution could be measured for materials with small particles by AFM.

\section{References}

(1) Nishijima, S.. Ishii, A., Kanazawa, K., Matsuoka, $S$. and Masuda, T., NRIM Fatigue Data Sheet Technical Document, (in Japanese), No. 5 (1989).

(2) Gotou, T., Study on Detection of Deterioration and Damage due to High Temperature Service Using Nondestructive Material Property Tests, Mitsubishi Juko (Giho, (in Japanese), Vol. 21, No. $3(1984)$, p. 1
(3) Murakami, Y., Itokazu, M. and Tanaka, K., Analysis of Triangular Pyramid Indentation by the Finite Element Method, Trans. Jpn. Soc. Mech. Eng. (in Japanese), Vol. 59, No. 559, A (1993), p. 835.

(4) Binnig, G., Rohrer, H., Gerber, Ch. and Weibel, E., Surface Studies by Scanning Tunneling Microscopy, Phys. Rev. Lett., Vol. 49 (1982), p. 57.

(5) Binnig, G., Quate, C.F. and Gerber, Ch., Atomic Force Microscope, Phys. Rev. Lett., Vol. 56 (1986), p. 930.

(6) Burnham, N.A. and Colton, R.J., Measuring the Nanomechanical Properties and Surface Forces of Materials Using an Atomic Force Microscope, J. Vac. Sci. Tech., A, Vol. 7, No. 4 (1989), p. 2906.

( 7 ) Hamada, E. and Kaneko, R., Micro-Tribological Evaluation of a Polymer Surface by Atomic Force Microscopes, Ultramicroscopy 42-44 (1992), p. 184.

(8) Nagashima, N. Matsuoka, S., Miyahara, K. and Masuda, H., Nanoscopic Hardness Measurement by Scanning Tunneling Microscope, Trans. Jpn. Soc. Mech. Eng. (in Japanese), Vol. 59, No. 564, A (1993), p. 2005.

(9) Japanese Industrial Standards (JIS), Method of Vickers Hardness Test, Z 2244\%1992. (in Japanese)

(10) Pethica, J.B., Hutchings, R. and Oliver, W.C., Hardness Measurement at Penetration Depths as Small as $20 \mathrm{~mm}$, Philos. Mag. A, Vol. 48, No. 4 (198.3), p. 593. 